VIVIANA LoZANo DUCUARA, EDWIN AlEXANDER HeNAO CONDE ${ }^{1}$

\title{
Seeds of Resistance: The Pijao Group, a Youth Process of Decolonisation and the Unity of the Pijao People
}

April 9th 2012 was the day that, in the Sociology Department of the National University of Colombia in Bogotá, the thoughts and feelings of five young people started to grow into something bigger. As sons and daughters of the large Natagaimas and Coyaimas territories we came together to name our nascent group as Grupo Pijao. This group is a seed that we continue to sow and harvest today in our territories through different strategies.

As the seed of our group grows, the ideas, forces and feelings that have been invested in this process have enriched the meaning and importance of our harvest. It is pleasing for us to witness the journey of this seed, which has accompanied our growth and help us transit from youth to adulthood. The emergence of this project can also be pictured as a group of adolescents wanting to build and fly their own kite. Following the trajectory of this metaphorical kite through the invisible currents of the wind, we continue propelling the flight of our own process as

I Viviana lozano Ducuara and Edwin Alexander Henao Conde are founders of Grupo Pijao; grupopijao@gmail.com

${ }^{2}$ This article has been translated by Diego Silva, Laëtitia Saint Laubert and Angus McNelly. This article was originally published in http://www.alternautas.net/blog/2020/6/22/seeds-ofresistance-the-pijao-group-a-youth-process-of-decolonisation-and-the-unity-of-the-pijao-people 
Indigenous People struggling for survival, to different distances and spaces of political, cultural and territorial life.

Between smiles, walks and words, as it is usually the case when we gather to weave knowledge together, we meet once again to remember our first encounter. For some of us it was a chance encounter, for others it was an intentional one, but we all remembered the spiritual forces of attraction that brought us to share a chicha [corn beer]. The act of sharing a totumada de chicha [bowl of chicha] from our territories is always a tempting call to reunite to seek individual growth from a collective gathering.

The themes and motives of our meetings have grown as much as each one of us. Recalling the old phrase "everything is more than the sum of its parts" allows us to recognise this fact today. This is a recognition that comes, not only from our perspective, but also from that of our friends and allies; those who have witness our growth in strength and importance for our youth, our communities and our territories.

The act of recounting some moments of our process as Grupo Pijao is without doubt an exercise of introspection for many of us: for those of us who have been present from the beginning, for those of us who have joined this shared challenge along the way, and we hope that it will be too, for those who will get to know us through this text. These words are filled with emotion and memory as we write them, and they will be when we read them and re-read them in the future, in our process of individual and collective transformation.

It is important to say that the first group of co-founders who decided, in 2012, to shape and give a name to this process (subsequently reaffirmed by so many bodies and visions that have been since added) was mainly composed of university students. The majority of us were students of the National University of Colombia under the age of 25 . Our living conditions as students motivated us to reflect and believe in this challenge. We were students arriving to the city from our communities in the Natagaimas and Coyaimas territories, as well as the Ortega and Chaparral territories, where we struggle for our survival as a people. We arrived to the city ladened with the hopes of our families to overcome, through our education 
and gaining a professional title, the socioeconomic limitations of a discriminatory, exploitative and subordinating economic system, endured by our communities for generations.

However, the gap between our places of origin and our new surroundings was accentuated from the moment of arrival at the most important and recognised university in the country, a place immersed in the living conditions of the big city, in its accelerated rhythm and high daily competitiveness. Here, the multi-ethnic and pluricultural wealth of the country and the different opportunities it could offer to its students, were lost in the university's institutionalized settings and in the standardized knowledge that it offered in the classroom. So evident was the need for an academic refuge, financial support for food and the cost of student living, as well as the need for strategies to overcome the situations of discrimination and social isolation in our everyday life, that the paisanas and paisanos begun to weave their own space. This common weaving gave us a sense of belonging, empowering us to continue facing and advancing on the journey that every one of us, together with their families, had begun.

Thus emerged the first strategy with which we arrived to our territories as Grupo Pijao, embracing the language and customs of our communities. Through this initiative, which we called Pre-Icfes and Pre-Universitarios, we sought to recognize the importance of supporting our families, our community and our friends. The Pre-Icfes workshops helped students in their last 3 years of high school to prepare for the national standard exam that all students must take before graduation. The Pre-Universitarios workshops helped high school graduates prepare for the tests of admission held by some public universities. We begun this initiative aware of the privilege position that we had as university students, not only to advance our personal lives as professionals, but also to use our education as a tool to assist with our communities' struggles and daily resistance in our territories.

From the first meetings around a bowl of chicha, the co-founders of the Pijao Group opened a critical reflection on the model of education and development that has been imposed in our territories. We saw this type of education as a recolonization model, where the only road for men's personal growth and capacity development is to become a soldier or policemen at the service of the country. In 
some cases, men are also taught business skills that can help them generate wealth through agricultural activities. For women, the pathway to self-fulfilment was related to their beauty and their housework skills, which can help them find a wealthy man, who treats them as "ladies" and who satisfies their family needs. This is what the school was teaching our youth.

No matter how much we drew insurgency discussing our dreams with friends in the group's hikes, bonfires, and bathing days in the creek, the river or the well, our conditions of possibility to fullfil these dreams were limited by an education system imposed upon us. We decided to do something about it out of strenght and love for our families and friends, some of whom had resigned to join the ranks of the army as soon as they turn eighteen, or to carry out help work in the town or the city. We thus created the Pre-Icfes and Pre-Universitarios workshops as a strategy to guide and accompany our paisanas and paisanos through alternative worlds. We begun the workshops in Natagaima with five groups of students and thanks to the voluntary work of our members and that of friends and allies who later joined us in the process. We met on Sundays from seven to twelve in the municipal school. The knowledge that came together in those classrooms motivated us to go beyond dominant teaching methodologies drawn from teaching guides and used by schoolteachers. Instead, we began to weave discussions and thematic reflections that were connected to our own realities. We found alternative ways to learn and teach geography, social sciences, Spanish, and even mathematics.

That was our first green shoot. Similar to the corn harvest, when a grain comes out to greet the sun in a new form (no longer as a grain but as a leaf), in the same way the first results of the workshops brought us joy and vitality. We understood the workshops not as producing knowledge for knowledge sake, despite the efforts of institutionalised education to indoctrinate us with a generalized understanding of the world. Instead, our encounters with and from our own ways of knowing, gave us the capacity to overcome our learned limitations. We begun to draft a new way of working based on our own language, based on what represents and identifies us. At this point we decided to change the name of the workshops and to redefine all the areas of our work. After discussing the meaning and sense of the workshops, a strategy that had significantly grown from its beginnings, we decided to change its 
name to Tejiendo saberes para la vida (Weaving knowledge for life). We wanted to take the strategy beyond a mere academic exercise that adhered to the demands of institutionalized education, to work from alternative ways of producing knowledge. Our objective was not to promote the individual accumulation of knowledge and prestige that comes from institutional markers of "who knows and who does not know". Our goals was rather to build a horizontal field between those who teach and those who learn, in addition to the production knowledge what could have a lived functionality.

\section{Speaking Pijaolly: Decolonising Thought and Language}

We use a voice that allows the reader to feel the soft texture of our accomplishments. We hope that these accomplishments greet the reader as seeds that open up revealing their first leaves to the world.. The lines in this text seek to communicate our understanding that to become someone valuable in life does not mean to become "a professional" - the proposition of "formal" education in a system driven by the production of citizens. On the contrary, becoming the subject that is promoted by the school system means for us the cultural annihilation of our people, as it implies the denial of who we are and what is ours. That is why our understanding of becoming someone valuable in life cannot be separated from those who already are valuable to us: our mothers and fathers, our ancestors, our territory, those who have created our legacy and who should not be forgotten. We take a moment to recognize that as we write this text we have not stopped breathing passionately, that the words in each line beat to the sound of our emotion as they bloom into the pages that make this text, that this text is rooted in a rhizomatic network of feelings that irrigates the land where we planted our dreams.

Through the "weaving knowledge" project we managed to decentralize the university. As the clocks of Dali melt through new territories, our time in the university became interlinked to our time back home, bridging the capital to our territories. We had a thirst for building knowledge from the diverse rural realities of our youth, depressed by state abandonment, the effects of social and armed conflict, and the standardization of education. We were able to build a workspace in the 
Casa Semillas, a three-story house set up by the NGO Grupo Semillas for organizational and community work in the municipality of Natagaima. This became our meeting point for a series of hikes that we organized throughout our territories seeking to read the messages that are etched in our sacred places. Each community, hill, lake, and waterfall that we visited opened the possibility of understanding our world so that we could explain it. The hikes became the activity that we most looked forward too. It was an additional strategy in our process to know, recognize, and appropriate our territory so that we could defend it. We called this strategy Caminos Pijao (Pijao Pathways).

Caminos Pijao set the standard for our touring of the territory with the firm intention of reading it carefully. For example, the group decided to hike the Pacandé Ancestral Mountain. We did this during Easter when there is a large influx of parishioners. While parishioners hiked the main path on the north face of the mountain, we took the old path on the south face, guided by the Mohán ${ }^{3}$ and the leaders of the Yacó Molana and Pacandé reservations. This path connects the ravines of the mountain with a route that was taken in the past by miners searching for gold. After several hours of hiking, reflection and teamwork, our group arrived at the summit of the mountain. We stopped to recover our breath through a harmonization ritual performed in front of the backdrop provided by the meandering Magdalena River. From that point, we could also see the dry lagoon from where the Coyaimas and Natagaimas peoples, according to our story of origin, emerged. These hikes were a big step in our process as we were able to invite the youth that participated in our workshops to take part in this practical exercise of self-recognition. It was a way of bringing together rural and urban youth through a shared territorial sentiment.

The years of 2013 and 2014 went by and the first workshop participants took their state exams. Many of them also took the admission exam to the National University of Colombia and other public universities. We had great results in the main harvest, which cultivated young people with their own life plans. Our youth also had very

\footnotetext{
${ }^{3}$ Ancestral doctor and Pijao authority
} 
good results in the exams, with many of them advancing to study Medicine, Physics, Chemistry, Engineering, and Human Sciences, at the National University and in other public universities of the country. At this point, the workshops were constituted as a framework fuelled by the overwhelming force of our youth and who had begun to recognize their value and the importance of their actions at the regional and national context.

The great responsibility that we acquired with our peoples revitalized us. It helped us to understand that it was necessary to weave our process with that of our elders, who had also struggle for our rights as people. We also begun to notice that the type of language we used to talk with each other made our communication more rapid and efficient. We begun to value the process of Hablar Pijadamente (Speaking Pijaolly): a way of speaking that mixes Spanish with ancestral and local vocabulary, and that we could include as part of our process. This is how our third strategy was born - Hablando Pijadamente: a congress to project us politically, to discuss and link our dreams with our experiences.

The first congress took place is a classroom of the sociology department of the National University of Colombia. Our professors Adolfo Triana Antorveza and Germán Pachón Gantiva attended this meeting. They had worked in our territory and fought for the rights of our communities. We were also joined by the members of the Grupo Pijao, which had grown from 5 to 15 students from different careers, universities and communities. The far-reaching conclusions of this space led to expansion of the group's objectives. These conclusions were communicated to the Pijao people at the commemoration for the recovery of the territory. For the past 40 years, this commemoration has been carried out at the Tinajas Reservation in Natagaima on the 4th of December. It provides our group with a setting to interweave our experience and dreams with our peoples' ancestral wisdom.

The objectives of the Grupo Pijao were no longer limited to providing academic support to our youth, or collaborating with other local organizations. Our objectives took on a territorial perspective seeking to support process of social organization, offering our knowledge, writing the history of our territory on the basis of what the Pijao elders have lived and remember, and walking our territories so that we can defend it from multiple threats. The group entered into the year 
2015 with these objectives. At the congress in Natagaima we remembered the setbacks we had experienced. However, as we drunk chicha, smoke tabacco and spat aguardiente, as part of a ritual, we also thought that these setbacks had only given us more strength to fulfill our agreed commitments and responsibilities.

"Weaving knowledge for life" had become institutionalized in our territories. The workshops continued at the request of our youth, institutions and communities. The workshops had become a beautiful initiative that did not rely on contracts or Franciscan altruism. Rather, it was an initiative born in our territory, and formulated with a clear objective by those of us studying in the capital. It represented the possibility of cultivating a grassroots process of resistance of a people whose history had been silenced. By 2015, the house of the Grupo Semillas no longer existed but the group refused to give up on having a space to meet and conspire. Thus, thanks to combined efforts that led to the organization of various activities to raise money, the Casa en el Aire was created: a second-floor apartment located in Natagaima. This space would allow the writing of a new page in our process, now populated by increasingly diverse members with interests that crossed the political, cultural, musical, social and youth sectors. The Case en el Aire was a new page were the new generation of the Group could write their dreams.

Through the exploration of alternative ways of learning we focused our efforts on helping our workshops' participants to create their own life projects. Together with the likes of Caminos Pijao and other activities, the workshops helped us to create Lazos Pijao (Pijao Ties): a way of working together with other local initiatives that targeted the youth. For example, some of our members attended the program on Environmental and Territorial Management offered by the University of Tolima with the help of the local Environmental Committee. Other of our members joined the Manuel Quintín Lame Agroecology School led by the NGO Grupo Semillas. In this way, our members developed and strengthened their leadership skills while supporting local initiatives that shared their yearning to cultivate a collective Pijao identiy.

With each new step we took, our group became stronger: from a single, simple stem it developed into a more complex, fully-grown plant as the seeds we were sowing began to grow. An expression of this growth was our participation in the Marcha 
Carnaval in Ibagué. This was our first experience as a collective taking to the streets and demanding that our territories be respected, our water protected and the common good of our peoples not divided. All of these actions were giving young people the tools that they needed to develop their own critical thinking and to interrogate their existence as heirs to the ancestral territories of Coyaima and Natagaima from the Gran Pueblo Pijao.

We were the expression of a process created to read reality from a territorial lens. How would we participate as a group in the traditional festivals of the territory? We came up with an idea while sharing a Totumada de Chicha y Poporoy - or Guarapo in the Casa en el Aire. We were going to choose an indigenous Queen to represent the young people of the Grupo Pijao in the local beauty pageant. With this event, a dialogue started around the role of women, their body and what it means to participate in a beauty pageant. This was, after all, an act of transgression: a beauty queen self identifying as indigenous. Unexpectedly, this initiative was enthusiastically supported by the members of our group, who decorated the candidate's float with symbols of our culture and with posters against mineral mining in the region. The float sparked a feeling of belonging in the local population, a feeling of belonging to our culture, to what social convention of the ideal and desirable has tried to steal from our people. Our candidate was not crown as beauty queen that day, but our entire community was crowned with the right to celebrate our culture, to drink our chicha and to redefine the sense of our traditions.

As our activities grew in number, launching many initiatives from the Casa en el Aire, the time had come to find a bigger space to continue weaving, and attracting more and more young people, to our process. One afternoon, we made the decision to design a logo that would summarize the identity and goal of our group. Moreover, after a very long discussion we redefined our group as the Grupo Pijao, Jóvenes caminando por la unidad de nuestro pueblo (Pijao Group, young people marching together for the unity of our people).

We decided we wanted to find a house with trees where we could continue building our community. Thus, six months after meeting at the Casa en el Aire, we were able to find another location thanks to the NGO Grupo Semillas. We decided not 
to call it Casa Semillas, as the first meeting place that this NGO had previously helped us establish. The name of our new meeting place would need to represent the unity of our youth, before indigenous organizations with a longer trajectory. A mural with that name would also need to project us politically to those who passed by and looked at our new meeting place. We decided to call it El Tambuche, a word that reflects the idea of cultural rooting. The word Tambo refers to the idea of home. Our people have used this word for a long time. It is part of our cultural legacy but it is a word that we share with other indigenous peoples too. The word Tambo can also means a trench. Thus, we also use Tambuche to refer to the new trenches that we need to dig up to further decolonize our way of thinking. El Tambuche is the very place where we sow the seeds of diversity and resistance.

Not only was that seed of our process anchoring its roots, its growth promised an abundant harvest. New leaders emerged from our ranks and prepared the soil for the planting of new crops. Some of our members became involved in politics as candidates for local offices, others became involved in the work of social and indigenous organizations in the region, and (yet) others assumed important roles in local cabildos, reservations, villages and families. We felt like the chicha when it ferments and is almost ready to drink. Aware of our growth we decided to participate in the '2016 vigils for peace', where we communicated our support to a peace process with social justice in Colombia. This declaration is still valid today, as we demand the implementation of the Peace process that was signed by the State and FARC in 2016. This will have to be an effort to connect the peoples in our territories, whose dreams have been affected by social inequality and marginalization, but whose struggle is finding strength in the recognition of our cultures and territories.

\section{Cultivating the Harvest: The National Meeting of the Pijao People for Unity, Resistance and Survival}

One of the main teachings that the Pijao Group has been able to bring to its members and allies, is to make of politics an everyday life practice rooted in different forms of expression, positioning and exchange. We aim to cultivate a 
legacy that redefines traditional ideas of what politics means through each one of the activities and strategies that we promote from a place of recognition of what is ours, what is local and native. We use the arts, music, story telling, games, gatherings, walks, festivals and collective learning as tools for the cultivation of social organization and carrying out political work for the defense of our territories and communities. Moreover, the strategic network carried out by some of our youth to approach and accompany our communities, has been one of the basis allowing our Group to be recognized by other regional organizations, such as the Asociación de Cabildos Indígenas del Tolima - ACIT (Association of Indigenous Councils of Tolima), the Consejo Regional Indígena del Tolima - CRIT (Regional Indigenous Council of Tolima), the Asociación de Cabildos Autónomos del Tolima (Association of Autonomous Indigenous Councils of Tolima) - FICAT, and the Asociación de Resguardos Indígenas del Tolima - ARIT (Association of Indigenous Reservatios of Tolima). These organizations are beginning to recognize the Grupo Pijao and its members as strategic actors to work with for the unity resistance and survival of the Pijao people.

Thus, in 2018 the Grupo Pijao was invited to the process of discussion and creation of the Plan Salvaguarda del Pueblo Pijao (Plan for the Protection of the Pijao People). The Salvaguarda plans respond to an order of the Constitutional court (through decision T-025 of 2004 and the Auto 004), by which the government must design and implement a series of plans to prevent the physical and cultural extinction of 34 indigenous communities in Colombia. Creating the plan for the Pijao People significantly nourished the discussions and reflections held within the Grupo Pijao about our identity, culture, the legitimacy of local authorities, the decolonization of thought and communication for the survival of our peoples. Since the plan was a state initiative, these discussions were taking place in an institutionalized setting of negotiation between the executive, represented by the ministry of interior and local communities, represented by indigenous regional organizations.

It is important to highlight that, whilst as members of the Grupo Pijao we have collaborated in this process with technical and logistical support, this in some cases has created internal tensions around the concept and understanding of 'authority'. 
In fact, in our communities we have been debating how local authority is created and recognized through a reflection on who speaks, who knows, and who decides for us. The support and participation of the Grupo Pijao in the different activities that have defined its process, would have not be possible without the previous work and relations that we have carried out with the youth in the communities that are today represented in the Salvaguarda process. The recognition and trust created by this work and the relations with those who joined our activities gradually opened the door to our participation in the Salvaguarda process beyond the technical and logistical.

With the patience and attention of those who know how to knit with a purpose and with a common goal, it was possible for us to help reinforce the stitches that were behind the creation of the Pijao People Salvaguarda Plan proposal. Therefore, our cultivated capacities allowed us to include our voice, our feelings and our claims in the commitments that the State and the Colombia society acquire for the protection of our communities through this plan.

In this process, it was possible to transcend the structure and methodologies that were proposed by the State. We created of our own spaces and methods claiming our identity and culture through our own ways of gathering, nourishing, talking and communicating. As we are strengthening our ways, we continue to resist and to survive in unity as a People. This work materialized in the Convite Nacional del Pueblo Pijao por la Unidad, la Resistencia y la Pervivencia (National Meeting of the Pijao People for Unity, Resistance and Survival) carried out the 14th of June 2018 in the Meche Reservation in San Cayetano, Coyaima, where we mandated as a People the stitches that would guide the chile knitting ${ }^{4}$ for our physical, cultural, and territorial survival.

\footnotetext{
${ }^{4}$ Chile is a fishing net. The authors refer to the knitting of a fishing net as a metaphor for community building.
} 


\section{Some Conclusive Stitches to Continue Establishing the Pomada}

The act of sharing some of the steps in the path of the Grupo Pijao is in itself an opportunity for self-reflection and self-knowledge. It is like witnessing the transformation of a seed into a new form of life. It represents the embracing of our memory and our path through small, medium and large victories, which today we treasure as the standards for our future knitting and growth.

Our main objective for the future is the cultivation of creative capacity, strength and critical thought, through reflexive dialogue and reflection with our communities and territories. We also want to continue emphasizing the central role of our youth, and the importance of taking their voices into account in regional processes of social organization. This is our contribution to the challenge of relating the different generations of our communities and local authorities.

The decolonization of thought, identity and language in the midst of consumerism and exploitation must be remembered and promoted in our daily lives. Thus, one of the most important lessons guiding our sowing and harvesting is to bring politics into every aspect and field of life.

We offer this article to the memory of Juan Manuel Ortíz Palomá and Luis Albert

Tovar Tapiero, who continue guiding our work through their love for humanity, our territory, communities, families and the Grupo Pijao. Thank you.

Writing by the steps of our process and knitted through one common feeling as People.

Responsible for the stitches: Viviana Lozano Ducuara, Edwin Alexander Henao Conde. Cofundadores Grupo Pijao.

\footnotetext{
${ }^{5}$ Pomada refers to the weights that are sowed into the fishing net so that it sinks into the water. The authors are building on the metaphor of knitting a fishing net as the process of community building.
} 
161 ALteRnAUtAS 7 (I) - JULY 2020

Ally that brought together the intention with the materialization: Diego Silva.

\section{References}

Documento técnico. Propuesta Plan Salvaguarda Pueblo Pijao 2018.

Mandato Convite Nacional del Pueblo Pijao por la Unidad, la Resistencia y la Pervivencia. 14 de junio de 2018.

Entrevista Edwin Alexander Henao Conde, Coordinador General Grupo Pijao.

Documentos de trabajo proyecto "Jóvenes Sujetos de Derechos por la Defensa de los Territorios". 2017. 